\section{Linear Adsorption of Nonionic Organic Compounds from Water onto Hydrophilic Minerals: Silica and Alumina}

\author{
YU-HONG SU, ${ }^{\dagger}, \ddagger$ YONG-GUAN ZHU, ${ }^{\dagger}$ \\ GUANGYAO SHENG, § AND \\ C A RY T. CH I O U *,\|,
}

Research Center for Eco-environmental Sciences, Chinese Academy of Sciences, Beijing, 100085, People's Republic of China, Department of Chemistry, Xinjiang University, Urumqi, Xinjiang 830046, People's Republic of China, Department of Crop, Soil, and Environmental Sciences, University of Arkansas, Fayetteville, Arkansas 72701,

U.S. Geological Survey, Box 25046, MS 408, Federal Center, Denver, Colorado 80225, and Department of Environmental Engineering and Sustainable Environment Research Center, National Cheng Kung University, Tainan 70101, Taiwan

To characterize the linear adsorption phenomena in aqueous nonionic organic solute-mineral systems, the adsorption isotherms of some low-molecular-weight nonpolar nonionic solutes (1,2,3-trichlorobenzene, lindane, phenanthrene, and pyrene) and polar nonionic solutes (1,3dinitrobenzene and 2,4-dinitrotoluene) from single- and binarysolute solutions on hydrophilic silica and alumina were established. Toward this objective, the influences of temperature, ionic strength, and $\mathrm{pH}$ on adsorption were also determined. It is found that linear adsorption exhibits low exothermic heats and practically no adsorptive competition. The solute-solid configuration and the adsorptive force consistent with these effects were hypothesized. For nonpolar solutes, the adsorption occurs presumably by London (dispersion) forces onto a water film above the mineral surface. For polar solutes, the adsorption is also assisted by polar-group interactions. The reduced adsorptive forces of solutes with hydrophilic minerals due to physical separation by the water film and the low fractions of the water-film surface covered by solutes offer a theoretical basis for linear solute adsorption, low exothermic heats, and no adsorptive competition. The postulated adsorptive forces are supported by observations that ionic strength or $\mathrm{pH}$ poses no effect on the adsorption of nonpolar solutes while it exhibits a significant effect on the uptake of polar solutes.

\section{Introduction}

Soil/solid organic-matter (SOM) content dictates the extent and mode of uptake of organic compounds by geologic materials. Normally, if natural solids contain more than $0.1-$

\footnotetext{
* Corresponding author phone: (+886 6) 235-3710; fax: (+886 6) 275-2790; e-mail: carychio@ncku.edu.tw.

Chinese Academy of Sciences.

‡ Xinjiang University.

$\$$ University of Arkansas.

"U.S. Geological Survey.

$\perp$ National Cheng Kung University.
}

$0.2 \%$ of SOM and little charcoal-like substance or soot, adsorption of low-polarity nonionic solutes from water by solid surfaces is insignificant compared to the concurrent solute partition into SOM (1-5); this is attributed to the strong competitive adsorption of water for usually polar mineral/ inorganic surfaces $(2,5)$. However, for solids containing little or no SOM, adsorption with mineral/inorganic surfaces becomes the major/dominant process, even if the overall uptake is weak. Although a significant advance has been achieved in modeling the uptake of organic ligands and ionizable solutes (e.g., carboxylic acids) by some hydrophilic minerals (6 and references therein), the mechanism for relatively weak adsorption of low-polarity nonionic solutes by these minerals remains to be elucidated. The latter subject has not been well attended in conventional adsorption studies, where such solutes or vapors normally condense under strong adsorptive forces onto solid surfaces (or the pore space), producing highly nonlinear isotherms with large exothermic heats. Knowledge on adsorption of low-polarity solutes on hydrophilic minerals is needed for fate assessments of various environmental chemicals (7-11).

It is recognized that adsorption isotherms of low-polarity nonionic organic solutes (e.g., lindane, chlorobenzenes, and PAHs) from water on virtually organic-free hydrophilic minerals (e.g., silica and alumina) and low-organic-carbon clays (e.g., kaolinite and smectite) are essentially linear over a wide range of relative concentrations $\left(C_{\mathrm{e}} / S_{\mathrm{w}}\right)(7-12)$, where $C_{\mathrm{e}}$ is the equilibrium solute concentration and $S_{\mathrm{w}}$ is the solute water solubility. In many of these systems, the isotherm linearity extends to $C_{\mathrm{e}} / S_{\mathrm{w}}>0.5(8,10)$. The adsorption data with organic-free silica and alumina suggest that in these solute-mineral systems water must be preferentially adsorbed, thus making the competitive solute adsorption weak and linear. The specific solute-mineral layout that yields linear solute adsorption, which resembles superficially the linear solute partition with SOM, has been a subject of interest to be further resolved, since the conventional adsorption isotherms are typically nonlinear and no significant solute partition with solid inorganic material is anticipated.

Characteristics for weak linear adsorption of low-polarity nonionic solutes (e.g., PAHs) on hydrophilic solids (e.g., alumina, silica, and iron oxide) include (i) a rapid solutionsolid equilibrium time (9); (ii) a dependence of the adsorption coefficient $\left(K_{\mathrm{d}}\right)$ on the surface area (SA) of a given mineral $(8,13)$; (iii) a dependence of $K_{\mathrm{d}}$ on solute water solubility $\left(S_{\mathrm{w}}\right)$ $(8,10)$; (iv) no marked dependence of $K_{\mathrm{d}}$ on solution $\mathrm{pH}$, ionic strength, and solid surface charge and its sign (10); and (v) the solute adsorption heat being less exothermic than the solute condensation heat from water (i.e., the reverse solute heat of solution, $-\Delta \bar{H}_{\mathrm{w}}$ ) (13). With noted low adsorption heats, the adsorption is envisioned by some researchers to be driven by a gain in solvent (water) entropy when the solutes detach from surrounding structured water to adsorb onto the solid $(8,13)$. Such a viewpoint is, however, not conciliatory with the significant (entropy-reducing) solute concentration onto or near the solid and the exothermic heat $(13,14)$ accompanying the adsorption. Generally, the adsorption of a dilute solute proceeds with an exothermic heat that is large enough to offset the overall reduction in system entropy (15). Up to now, the particular solute-solid assembly leading to weak linear solute adsorption remains to be scrutinized.

With the stated characteristics of nonionic solutes on hydrophilic minerals, it is conceivable that a layer (film) of water adheres strongly on mineral surfaces (16); hence it can be hypothesized that the solutes could only adsorb weakly with reduced forces from minerals onto the water layer. If 


\section{TABLE 1. Physicochemical Properties of the Organic Compounds Used in Adsorption Experiments ${ }^{a}$}

\begin{tabular}{|c|c|c|c|c|c|c|c|}
\hline compound & abbrev. & MW & $\rho$ & $\mathrm{mp}$ & $S_{w}$ & $\Delta \overline{\boldsymbol{H}}_{\mathrm{w}}$ & $\log K_{\mathrm{ow}}$ \\
\hline 1,2,3-trichlorobenzene & TCB & 181.5 & 1.45 & 53 & 16.3 & $\mathrm{NA}^{b}$ & 4.04 \\
\hline lindane & LIN & 290.9 & 1.87 & 113 & 7.87 & NA & 3.72 \\
\hline phenanthrene & $\mathrm{PHN}$ & 178.2 & 1.17 & 101 & 1.29 & 40.0 & 4.46 \\
\hline pyrene & PYR & 202.3 & 1.27 & 156 & 0.135 & 45.3 & 4.88 \\
\hline 1,3-dinitrobenzene & DNB & 168.1 & 1.37 & 90 & 533 & 26.8 & 1.49 \\
\hline 2,4-dinitrotoluene & DNT & 182.1 & 1.52 & 71 & 300 & NA & 1.98 \\
\hline
\end{tabular}

${ }^{a} \mathrm{MW}=$ Molecular weight; $\rho=$ density at room temperature $(\mathrm{g} / \mathrm{mL}) ; \mathrm{mp}=$ melting point $\left({ }^{\circ} \mathrm{C}\right) ; S_{\mathrm{w}}=$ water solubility at $25^{\circ} \mathrm{C}(\mathrm{mg} / \mathrm{L}) ; \Delta \bar{H}_{\mathrm{w}}=\mathrm{molar}$ heat of solution in water at $25^{\circ} \mathrm{C}(\mathrm{kJ} / \mathrm{mol}) ; K_{\mathrm{ow}}=$ octanol-water partition coefficient. The density $(\rho)$, mp, $S_{\mathrm{w}}$, and $K_{\mathrm{ow}} \mathrm{values}$ are from those cited in Mackay et al. (19-22) except those of 1,3-dinitrobenzene from Syracuse Research Corporation database (23). The $\Delta \bar{H}_{\mathrm{w}}$ values of PHN and PYR are from May et al. (24) and that of DNB is from Li et al. (25). ${ }^{b}$ NA = not available.

such adsorbed solutes take up a small fraction of the relatively energetically uniform water surface, the adsorption will then be linear and noncompetitive; it would also display a low exothermic heat, to the extent that the adsorbed solutes do not form a separate phase. To avoid the difficulty in determining the water-film SA, the latter is approximated to equal the dry-mineral surface. The theoretical solute monolayer capacity with the water film surface may then be established to determine the fraction of film SA covered by the solute. To this effect, a solid (adsorbent) with a SA of $1000 \mathrm{~m}^{2} / \mathrm{g}$ adsorbing a substance of ca. $1 \mathrm{~g} / \mathrm{mL}$ in density will have an adsorbed monolayer capacity (AMC) of ca. 0.25 $\mathrm{mL} / \mathrm{g}$ (17). The AMC values in units of adsorbed volume per solid mass are fairly constant for different adsorbates (solutes) on a porous solid (15). Thus, by using the linear relation between AMC (volume/mass) and solid SA, the AMC (mass/ mass) for a solute with the water film of a solid can be computed as follows to test the requirement for linear noncompetitive solute adsorption:

$$
\operatorname{AMC}(\mathrm{mg} / \mathrm{g})=250 \rho(\mathrm{SA} / 1000)
$$

where $\rho$ is the solute density $(\mathrm{g} / \mathrm{mL})$ and SA is the solid's surface area $\left(\mathrm{m}^{2} / \mathrm{g}\right)$.

The primary objectives of this study are (i) to examine the competitive adsorption, if any, between nonionic solutes with hydrophilic minerals and (ii) to determine the fraction of water-film surface covered by the solutes for verifying the consistency with linear adsorption behavior. This study is warranted for model validation and for assessing the influence of coexisting solutes on the adsorption of a given nonionic solute in multi-solute natural systems. In this work, the adsorption isotherms of several nonpolar nonionic compounds (1,2,3-trichlorobenzene, lindane, phenanthrene, and pyrene) and polar nonionic compounds (2,4-dinitrotoluene and 1,3-dinitrobenzene) as single and binary solutes on pure silica and alumina were obtained to examine the competitiveness of the solute adsorption. Organic-free synthetic silica and alumina with high SAs were employed to enhance the accuracy of the adsorption data. To eliminate complications of the solute uptake by trace SOM in natural solids, no natural clay minerals (e.g., kaolinite and montmorillonite) were used in the present work. Inclusion of polar nonionic solutes into the present study expands the scope of the investigation. In addition to measuring the adsorption isotherms at room temperature $\left(25 \pm 1{ }^{\circ} \mathrm{C}\right)$, the isotherms of some solutes at 45 ${ }^{\circ} \mathrm{C}$ were also secured in order to determine the adsorption heats for comparison with earlier reported values.

\section{Experimental Section}

Adsorbents. Two highly pure synthetic mineral oxides (adsorbents) with large specific surface areas were selected for experiments. An active silica gel, short as "silica", with a particle size of $100-200 \mu \mathrm{m}$ and an average pore size of 6 $\mathrm{nm}$, was obtained from Scientific Adsorbents Inc. (Atlanta,
GA). This sample has a SA by the BET- $\mathrm{N}_{2}$ method of 563 $\mathrm{m}^{2} / \mathrm{g}$, as determined with a Gemini 2360 surface-area analyzer from Micromeritics. An activated aluminum oxide (neutral, Brockmann 1), short as "alumina", having a particle size of ca. 150 mesh and a BET SA of $155 \mathrm{~m}^{2} / \mathrm{g}$ (reported in the Aldrich Catalog) was obtained from Aldrich. Both solids show no detectable organic carbon level $(<0.01 \%$, by Leco WR112 Instrument). The respective points of zero charge (PZC) for silica and alumina are 5.7 and 7.0 (by electrophoretic mobility), 5.2 and 6.8 (potentiometric titration) (16), and 5.3 and 6.3 (pH-drift) (18). From the potentiometric titration, the acidity constants of surface hydroxyls for silica are 3.3 $\left(p \mathrm{~K}_{\mathrm{a} 1}\right)$ and $6.9\left(p \mathrm{~K}_{\mathrm{a} 2}\right)$. These constants for alumina are 5.2 and 8.5.

Solutes. 1,2,3-Trichlorobenzene (TCB) (purity, 99\%), lindane (LIN) (97\%), phenanthrene (PHN) (98\%), pyrene (PYR) (98\%), 1,3-dinitrobenzene (DNB) (99.3\%) and 2,4dinitrotoluene (DNT) (99.4\%) were purchased from SigmaAldrich Co. They all were used as solutes in adsorption experiments without further purification. The fundamental physicochemical properties of these solutes are given in Table 1.

Adsorption Isotherms. A series of water solutions with a fixed level of background salts $\left(0.01 \mathrm{M}\right.$ or $0.05 \mathrm{M} \mathrm{CaCl}_{2}$ plus $400 \mathrm{mg} / \mathrm{L} \mathrm{NaN}_{3}$ ) and varied levels of a test solute (or binary solutes) were prepared using either $15-\mathrm{mL}$ or $30-\mathrm{mL}$ centrifuge tubes. For a solute-solid pair, fixed amounts of the solid were added to the solute solutions for determining the isotherm. The solid-to-solution ratios $(\mathrm{w} / \mathrm{v})$ ranged between $1: 3$ and 1:4 for TCB, LIN, DNB, and DNT and between 1:10 and 1:20 for PHN and PYR depending on specific solutesolid systems. The solution volumes were $10 \mathrm{~mL}$ for TCB, LIN, DNB, and DNT and $20 \mathrm{~mL}$ for PHN and PYR. The solidsolution mixtures were equilibrated for $48 \mathrm{~h}$ on a horizontalmotion shaker under a nearly constant temperature of $25 \pm$ $1{ }^{\circ} \mathrm{C}$ or $45 \pm 1{ }^{\circ} \mathrm{C}$, maintained by a thermostated water bath. The differences in metal oxide crystal properties at the two temperatures were neglected. Preliminary experiments indicated that all solid-solution mixtures reached equilibrium in $48 \mathrm{~h}$. Other than PHN and DNT from $0.01 \mathrm{M} \mathrm{CaCl}_{2}$ on alumina at $25^{\circ} \mathrm{C}$ and $\mathrm{pH}=8$ adjusted using $0.1 \mathrm{M} \mathrm{NaOH}$, all solid-solution mixtures were equilibrated without $\mathrm{pH}$ adjustment. After equilibration, the solution and solid phases were separated by centrifugation at $3000 \mathrm{~g}$. Aliquots of supernatant solutions were then removed with a pipet and extracted with $n$-hexane for analysis of the solute concentration $\left(C_{\mathrm{e}}\right)$. Remaining supernatant solutions were used to determine equilibrium $\mathrm{pH}$.

In the binary-solute experiments, concentrations of the two solutes were chosen such that they had about equal initial relative concentrations $\left(C_{\mathrm{i}} / S_{\mathrm{w}}\right)$, where $C_{\mathrm{i}}$ is the initial solute concentration and $S_{\mathrm{w}}$ is the solute solubility. This was done to ensure that the two solutes have comparable competitive adsorption potentials, if the adsorption on the solid is competitive in nature. 
In all experiments with the solid-solution ratios used, the solute concentrations in water following the equilibration exhibited a significant (usually, 30-70\%) decrease relative to the respective control solutions (containing only solutes and background salts without solids) for improving accuracies of the established adsorption isotherms. The recoveries of control solute samples, by the method described below, were $96.7 \pm 1.4 \%$ for TCB; $98.5 \pm 4.0 \%$ for LIN; $89.3 \pm 1.0 \%$ for PHN; $97.3 \pm 3.7 \%$ for PYR; $95.2 \pm 1.8 \%$ for DNB; and $91.3 \pm$ $1.5 \%$ for DNT. Amounts of the solute adsorbed by the solid were determined by differences of the measured solute concentrations between the control and study samples.

Solute Analyses. Aliquots of water solutions were extracted with $n$-hexane. Solute concentrations were quantified by gas chromatography using the external standards of respective solutes in $n$-hexane analyzed in conjunction with the experimental samples. LIN and TCB in extracts were quantified by an Agilent 6820 gas chromatograph with a ${ }^{63} \mathrm{Ni}$ electron capture detector (ECD) and a DB-1 capillary column (0.53 $\mathrm{mm} \times 15 \mathrm{~m}, 0.5 \mu \mathrm{m}$ thick); extracts of DNB, DNT, PHN and PYR were also analyzed by the same chromatograph using a flame ionization detector (FID) and a HP-5 MS capillary column $(0.32 \mathrm{~mm} \times 30 \mathrm{~m}, 0.25 \mu \mathrm{m}$ thick $)$.

Data Analyses. Isotherms for each solute-solid system were constructed by plotting the mass of solute adsorbed per unit weight of the solid (adsorbent), $Q(\mathrm{mg} / \mathrm{kg}$ ), against the respective equilibrium solute concentration, $C_{\mathrm{e}}(\mathrm{mg} / \mathrm{L})$. In view that the isotherms for all test solutes were essentially linear, the distribution coefficients $\left(K_{\mathrm{d}}\right)$ and the standard errors $( \pm$ SE) for individual solute-solid pairs were computed using a linear statistical program (SPSS Version 11.5). Average $K_{\mathrm{d}}$ and associated SE values at $P<0.01$ are listed in Table 2.

\section{Results and Discussion}

The representative adsorption isotherms of selected nonpolar nonionic compounds (TCB, LIN, PHN, and PYR) and polar nonionic compounds (DNB and DNT), as single and binary solutes, on silica and alumina at $25( \pm 1)^{\circ} \mathrm{C}$ and $45( \pm 1){ }^{\circ} \mathrm{C}$ are presented in Figures 1-4, in which the mass of adsorbed solute per unit weight of the solid $(Q)$ is plotted against the equilibrium solute concentration in water $\left(C_{\mathrm{e}}\right)$. As shown, the isotherms are all practically linear, with $C_{\mathrm{e}} / S_{\mathrm{w}}$ extended to 0.14 for DNT/alumina and 0.56 for PHN/silica. This high isotherm linearity is similar to that found earlier in uptakes of PHN and other PAHs by silica and alumina $(8,9,13)$. Treating these isotherms in linear form with zero intercept, the linear solute adsorption coefficients $\left(K_{\mathrm{d}}\right)(\mathrm{L} / \mathrm{kg})$ for related solute-solid systems are determined (Table 2). As noted, whereas the $K_{\mathrm{d}}$ is the highest for the least water-soluble PYR, the $K_{\mathrm{d}}$ for relatively soluble polar DNB is also quite appreciable (especially, the $K_{\mathrm{d}}$ with alumina). Overall, the $K_{\mathrm{d}}$ values for all solutes with either silica or alumina are not dictated primarily by their water solubilities $\left(S_{\mathrm{w}}\right)$ or octanol-water partition coefficients $\left(K_{\text {ow }}\right)$, meaning that the solute hydrophilicity is not the predominant determinant of $K_{\mathrm{d}}$. In all $\mathrm{pH}$-unadjusted adsorption experiments, the final solution $\mathrm{pH}$ values were $5.25 \pm 0.10$ for silica and $6.28 \pm 0.10$ for alumina, all being close to the mineral PZC.

With the hypothesis that the solute adsorbs on top of the water film over the mineral (solid), one would anticipate the $K_{\mathrm{d}}$ for a solute with a given mineral to be largely proportional to the solid SA and the heat of adsorption per mole of the solute $\left(\Delta \bar{H}_{\mathrm{ad}}\right)$ to be independent of the $K_{\mathrm{d}}$. To the SA effect, the present PHN $K_{\mathrm{d}}$ of 6.48 with the silica $\left(\mathrm{SA}=563 \mathrm{~m}^{2} / \mathrm{g}\right.$ ) is similar in magnitude to the PHN $K_{\mathrm{d}}$ of 3.08 with silica gel $150\left(\mathrm{SA}=314 \mathrm{~m}^{2} / \mathrm{g}\right)$ and of 4.65 with silica gel $40(\mathrm{SA}=521$ $\mathrm{m}^{2} / \mathrm{g}$ ), reported by Huang et al. (9). Similarly, on the SA basis, the present PYR $K_{\mathrm{d}}$ of 12.0 with the alumina $\left(\mathrm{SA}=155 \mathrm{~m}^{2} / \mathrm{g}\right.$ ) is of the same order of magnitude as that (0.231) with
TABLE 2. Adsorption Coefficients $\left(K_{\mathrm{d}}\right)$ of Selected Organic Solutes on Silica and Alumina

\begin{tabular}{lcccc}
\multicolumn{1}{c}{$\begin{array}{c}\text { solute/ } \\
\text { cosolute }\end{array}$} & $\boldsymbol{t}\left({ }^{\circ} \mathbf{C}\right)$ & $\begin{array}{c}\boldsymbol{K}_{\mathbf{d}} \text { (silica) } \\
\text { (L/kg) }\end{array}$ & $\begin{array}{c}\boldsymbol{K}_{\mathbf{d}} \text { (alumina) } \\
\text { (L/kg) }\end{array}$ & $\begin{array}{c}\text { ionic strength } \\
\text { (with } \text { CaCl }_{2} \text { ) }\end{array}$ \\
TCB & 25 & $5.49 \pm 0.29$ & $0.98 \pm 0.05$ & $0.01 \mathrm{M}$ \\
TCB & 45 & $4.13 \pm 0.43$ & $0.63 \pm 0.04$ & $0.01 \mathrm{M}$ \\
TCB/LIN & 25 & $5.37 \pm 0.60$ & $0.92 \pm 0.14$ & $0.01 \mathrm{M}$ \\
TCB/PHN & 25 & $5.81 \pm 0.19$ & $0.93 \pm 0.05$ & $0.01 \mathrm{M}$ \\
LIN & 25 & $7.37 \pm 0.48$ & $1.53 \pm 0.07$ & $0.01 \mathrm{M}$ \\
LIN & 25 & $7.65 \pm 0.53$ & $1.20 \pm 0.13$ & $0.05 \mathrm{M}$ \\
LIN & 45 & $4.61 \pm 0.34$ & $0.93 \pm 0.05$ & $0.01 \mathrm{M}$ \\
LIN/PHN & 25 & $7.70 \pm 0.34$ & $1.51 \pm 0.07$ & $0.01 \mathrm{M}$ \\
LIN/TCB & 25 & $7.56 \pm 0.27$ & $1.43 \pm 0.13$ & $0.01 \mathrm{M}$ \\
PHN & 25 & $6.48 \pm 0.18$ & $2.28 \pm 0.10$ & $0.01 \mathrm{M}$ \\
PHN & 25 & $6.66 \pm 0.44$ & $2.37 \pm 0.22$ & $0.05 \mathrm{M}$ \\
PHN (pH $=8)$ & 25 & & $2.20 \pm 0.11$ & $0.01 \mathrm{M}$ \\
PHN/TCB & 25 & $6.39 \pm 0.36$ & $2.24 \pm 0.11$ & $0.01 \mathrm{M}$ \\
PHN/PYR & 25 & $6.34 \pm 0.13$ & $2.19 \pm 0.23$ & $0.01 \mathrm{M}$ \\
PHN & 45 & $4.31 \pm 0.12$ & $1.49 \pm 0.08$ & $0.01 \mathrm{M}$ \\
PHN/LIN & 25 & $6.14 \pm 0.66$ & $2.71 \pm 0.16$ & $0.01 \mathrm{M}$ \\
PHN/DNT & 25 & $5.90 \pm 0.37$ & $2.41 \pm 0.17$ & $0.01 \mathrm{M}$ \\
PYR & 25 & $18.9 \pm 0.33$ & $12.0 \pm 0.43$ & $0.01 \mathrm{M}$ \\
PYR & 25 & $18.6 \pm 0.41$ & $11.5 \pm 0.52$ & $0.05 \mathrm{M}$ \\
PYR & 45 & $10.5 \pm 0.29$ & $7.45 \pm 0.44$ & $0.01 \mathrm{M}$ \\
PYR/PHN & 25 & $18.5 \pm 1.08$ & $11.6 \pm 0.55$ & $0.01 \mathrm{M}$ \\
DNT & 25 & $4.77 \pm 0.37$ & $4.48 \pm 0.04$ & $0.01 \mathrm{M}$ \\
DNT & 25 & $3.77 \pm 0.10$ & $1.36 \pm 0.04$ & $0.05 \mathrm{M}$ \\
DNT (pH $=8)$ & 25 & & $53.7 \pm 4.46$ & $0.01 \mathrm{M}$ \\
DNT & 45 & $2.98 \pm 0.27$ & $2.03 \pm 0.17$ & $0.01 \mathrm{M}$ \\
DNT/DNB & 25 & $4.82 \pm 0.30$ & $4.32 \pm 0.34$ & $0.01 \mathrm{M}$ \\
DNT/PHN & 25 & $4.95 \pm 0.51$ & $4.43 \pm 0.39$ & $0.01 \mathrm{M}$ \\
DNB & 25 & $3.17 \pm 0.24$ & $3.63 \pm 0.12$ & $0.01 \mathrm{M}$ \\
DNB & 45 & $2.17 \pm 0.08$ & $2.22 \pm 0.22$ & $0.01 \mathrm{M}$ \\
DNB/DNT & 25 & $3.30 \pm 0.14$ & $3.63 \pm 0.18$ & $0.01 \mathrm{M}$
\end{tabular}

a If not specified, the $\mathrm{pH}$ values of solute-solid suspensions are 5.25 \pm 0.10 for silica and $6.28 \pm 0.10$ for alumina.

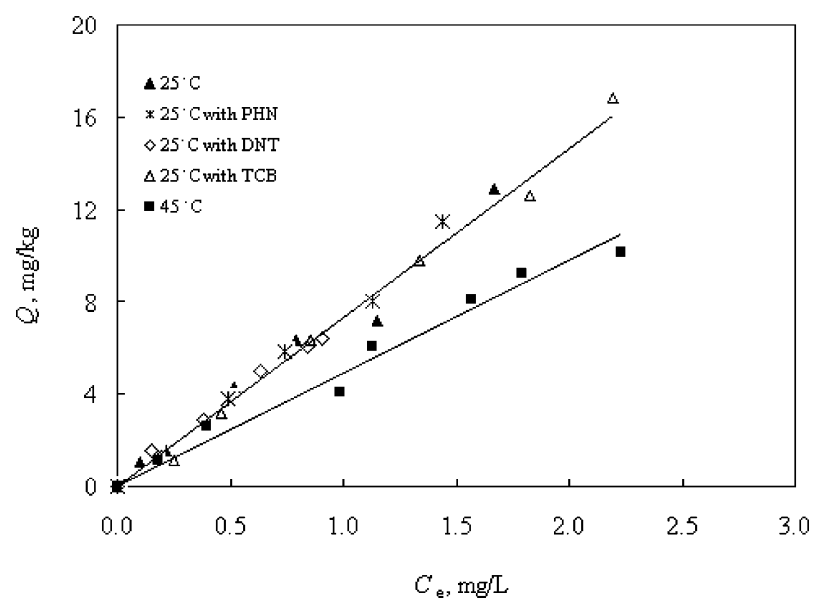

FIGURE 1. Adsorption isotherms of $\mathrm{LIN}$ from $0.01 \mathrm{M} \mathrm{CaCl}_{2}$ on silica at $\mathrm{pH}=\mathbf{5 . 2 5} \pm \mathbf{0 . 1 0}$.

$\alpha$-alumina (SA $=11.7 \mathrm{~m}^{2} / \mathrm{g}$ ) observed by Mader et al. (10). To the adsorption heat effect, the solute molar heats of adsorption are first obtained by application of the van't Hoff equation using the linear adsorption coefficients (i.e., $K_{\mathrm{d}}$ values) at two temperatures, i.e.,

$$
\Delta \bar{H}_{\mathrm{ad}}=-2.303 R\left[\frac{\log \left(K_{\mathrm{d}, 2} / K_{\mathrm{d}, 1}\right)}{1 / T_{2}-1 / T_{1}}\right]
$$

where $\Delta \bar{H}_{\text {ad }}$ is adsorption heat per mole of the solute $(\mathrm{kJ} /$ $\mathrm{mol}), R$ is the gas constant $(8.31 \mathrm{~J} / \mathrm{K}-\mathrm{mol})$, and $K_{\mathrm{d}, 1}$ and $K_{\mathrm{d}, 2}$ 


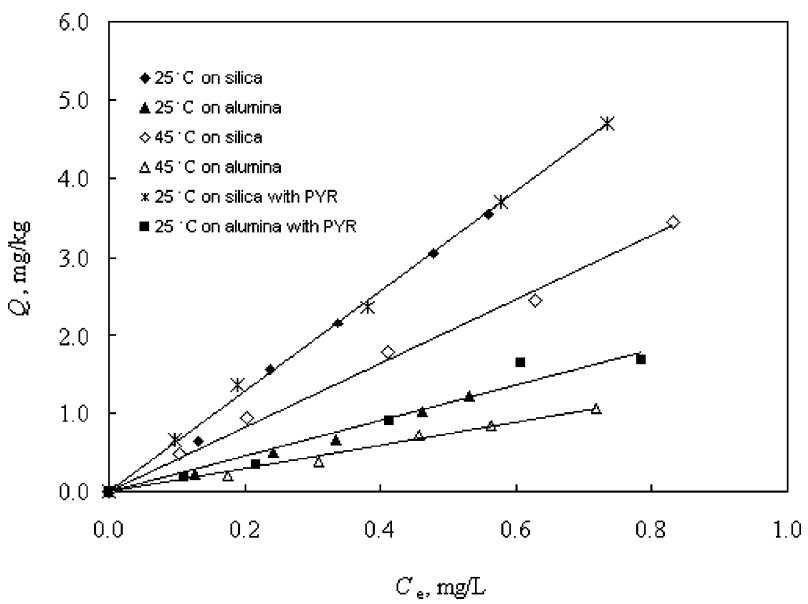

FIGURE 2. Adsorption isotherms of PHN from $0.01 \mathrm{M} \mathrm{CaCl}_{2}$ on silica at $\mathbf{p H}=\mathbf{5 . 2 5} \pm \mathbf{0 . 1 0}$ and on alumina at $\mathrm{pH}=\mathbf{6 . 2 8} \pm \mathbf{0 . 1 0}$.

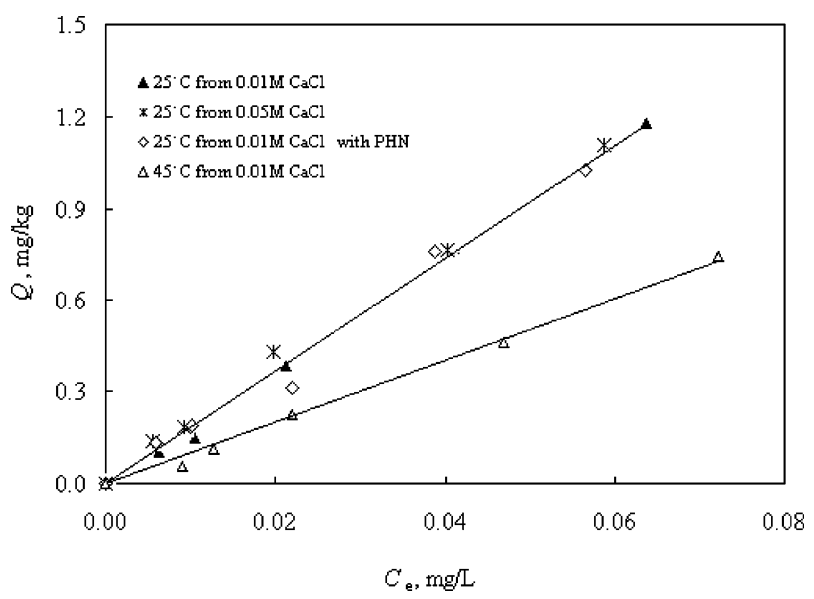

FIGURE 3. Adsorption isotherms of PYR from $0.01 \mathrm{M}$ and $0.05 \mathrm{M}$ $\mathrm{CaCl}_{2}$ on silica at $\mathrm{pH}=\mathbf{5 . 2 5} \pm \mathbf{0 . 1 0}$.

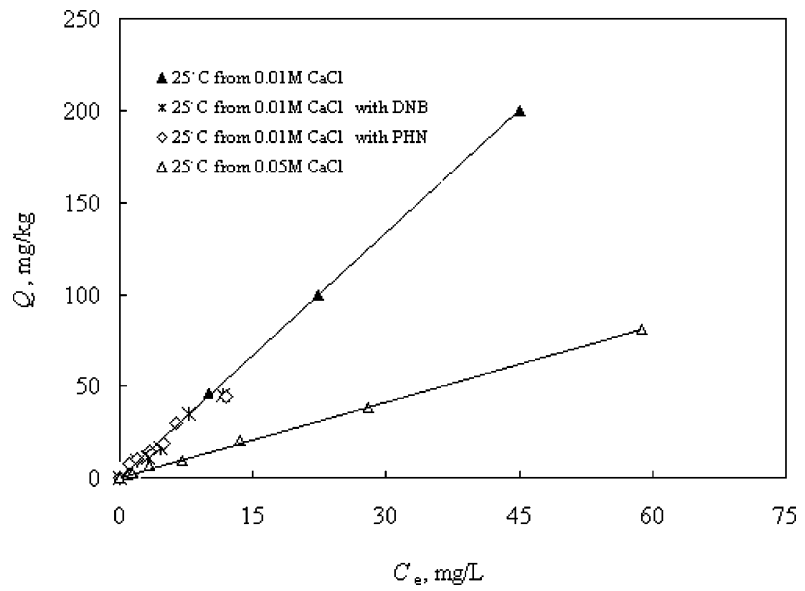

FIGURE 4. Adsorption isotherms of DNT from $0.01 \mathrm{M}$ and $0.05 \mathrm{M}$ $\mathrm{CaCl}_{2}$ on alumina at $\mathrm{pH}=6.28 \pm 0.10$.

are (linear) adsorption coefficients at absolute temperatures $T_{1}$ and $T_{2}$. Using the present $K_{\mathrm{d}}$ at 25 and $45^{\circ} \mathrm{C}$ under $0.01 \mathrm{M}$ $\mathrm{CaCl}_{2}$, the $\Delta \bar{H}_{\mathrm{ad}}$ is $-18.5 \mathrm{~kJ} / \mathrm{mol}$ on silica and $-19.6 \mathrm{~kJ} / \mathrm{mol}$ on alumina for LIN; $-16.1 \mathrm{~kJ} / \mathrm{mol}$ on silica and $-16.8 \mathrm{~kJ} / \mathrm{mol}$ on alumina for PHN; $-23.2 \mathrm{~kJ} / \mathrm{mol}$ on silica and $-18.8 \mathrm{~kJ} /$ mol on alumina for PYR; $-14.9 \mathrm{~kJ} / \mathrm{mol}$ on silica and -19.4 $\mathrm{kJ} / \mathrm{mol}$ on alumina for DNB. These values compare well with the reported $\Delta \bar{H}_{\text {ad }}$ of ca. $-20.9 \mathrm{~kJ} / \mathrm{mol}$ for LIN on aquifer sand $(11) ;-12.6$ to $-17.9 \mathrm{~kJ} / \mathrm{mol}$ for PHN on silica gel 150 and -19.6 to $-22.8 \mathrm{~kJ} / \mathrm{mol}$ for PHN on silica gel 40 (13); and
TABLE 3. AMC, $S_{\mathrm{w}} K_{\mathrm{d}}$, and $S_{\mathrm{w}} K_{\mathrm{d}} / A M C$ Values of Solute-Solid Systems at $25{ }^{\circ} C^{a}$

\begin{tabular}{lccc}
\multicolumn{1}{c}{ solute/solid } & AMC & $\boldsymbol{S}_{\mathrm{w}} \boldsymbol{K}_{\mathbf{d}}$ & $\boldsymbol{S}_{\mathrm{w}} \boldsymbol{K}_{\mathbf{d}} / \mathbf{A M C}$ \\
TCB/silica & 204 & $8.95 \mathrm{E}-2$ & $4.39 \mathrm{E}-4$ \\
TCB/alumina & 56.2 & $1.60 \mathrm{E}-2$ & $2.84 \mathrm{E}-4$ \\
LIN/silica & 263 & $5.80 \mathrm{E}-2$ & $2.21 \mathrm{E}-4$ \\
LIN/alumina & 72.5 & $1.22 \mathrm{E}-2$ & $1.66 \mathrm{E}-4$ \\
PHN/silica & 165 & $8.36 \mathrm{E}-3$ & $5.07 \mathrm{E}-5$ \\
PHN/alumina & 45.3 & $2.94 \mathrm{E}-3$ & $6.49 \mathrm{E}-5$ \\
PYR/silica & 179 & $2.55 \mathrm{E}-3$ & $5.19 \mathrm{E}-5$ \\
PYR/alumina & 49.2 & $1.62 \mathrm{E}-3$ & $3.29 \mathrm{E}-5$ \\
DNT/silica & 214 & 1.43 & $6.68 \mathrm{E}-3$ \\
DNT/alumina & 58.9 & 1.34 & $2.28 \mathrm{E}-2$ \\
DNB/silica & 193 & 1.69 & $8.75 \mathrm{E}-3$ \\
DNB/alumina & 53.1 & 1.94 & $3.65 \mathrm{E}-2$
\end{tabular}

a $\mathrm{AMC}=$ adsorbed solute monolayer capacities on solids $(\mathrm{mg} / \mathrm{g})$; $S_{\mathrm{w}} K_{\mathrm{d}}=$ maximum solute concentrations on solids $(\mathrm{mg} / \mathrm{g})$, where the $K_{\mathrm{d}}$ are values at $0.01 \mathrm{M} \mathrm{CaCl} 2 ; S_{\mathrm{w}} K_{\mathrm{d}} / \mathrm{AMC}=$ maximum fractions of monolayers occupied by solutes.

$-20.8 \mathrm{~kJ} / \mathrm{mol}$ for PYR on $\alpha$-alumina (10). Thus, the results from present and earlier studies are mutually consistent and well in line with theoretical expectations.

As seen, all solute $\Delta \bar{H}_{\text {ad }}$ values are notably exothermic but less in extent than the respective solute $-\Delta \bar{H}_{\mathrm{w}}$ values; here $\Delta \bar{H}_{\mathrm{w}}$ is $40.0 \mathrm{~kJ} / \mathrm{mol}$ for PHN (24), $45.3 \mathrm{~kJ} / \mathrm{mol}$ for PYR (24), and $26.8 \mathrm{~kJ} / \mathrm{mol}$ for DNB $(25)$ at $\sim 25^{\circ} \mathrm{C}$. The magnitudes and signs of $\Delta \bar{H}_{\text {ad }}$ relative to $-\Delta \bar{H}_{\mathrm{w}}$ manifest that adsorbed solutes do not form a condensed phase on mineral surfaces; if a condensed phase were formed, the $\Delta \bar{H}_{\text {ad }}$ would be more exothermic than $-\Delta \bar{H}_{\mathrm{w}}$ because the solute condensation heat $\left(-\Delta \bar{H}_{\mathrm{w}}\right)$ is a component of the adsorption heat (26). A typical solute condensation effect is illustrated by PHN on graphite (13), where $\Delta \bar{H}_{\text {ad }}$ is about $-47.1 \mathrm{~kJ} / \mathrm{mol}$ and the isotherm is highly nonlinear (with a concave downward shape). This disparate adsorption characteristic is attributed to the low affinity of water for graphite that makes the solute (PHN) a powerful competitor over water for adsorptive condensation on the solid surfaces. The present system is also dissimilar to the complex formation of reactive solutes (e.g., carboxylic acids) with mineral surface sites (6), since this occurrence would likely result in high exothermic heats and a nonlinear uptake due to site saturation.

The present study manifests the absence of competitive adsorption between coexisting solutes with hydrophilic minerals. This effect is attributed to the weak solute adsorption over a strongly adsorbed water film, on which the solute molecules occupy supposedly only a small fraction of the relatively (energetically) uniform surface. Under this condition, the adsorbed solute is at a discrete molecular state rather than at a condensed state (because the latter situation will make $\Delta \bar{H}_{\text {ad }}$ more exothermic than $-\Delta \bar{H}_{\mathrm{w}}$ ). Using eq 1 , the AMC values are obtained for all solutes. Taking the water solubility $\left(S_{\mathrm{w}}\right)$ as the linear-adsorption limit, the highest adsorbed solute concentration on the solid will then be $S_{\mathrm{w}} K_{\mathrm{d}}$ and the largest fraction of the monolayer occupied by the solute will be $S_{\mathrm{w}} K_{\mathrm{d}} / \mathrm{AMC}$.

Calculated AMC, $S_{\mathrm{w}} K_{\mathrm{d}}$, and $S_{\mathrm{w}} K_{\mathrm{d}} / \mathrm{AMC}$ values for lowpolarity TCB, LIN, PHN, and PYR are listed in Table 3. As found, the $S_{\mathrm{w}} K_{\mathrm{d}} / \mathrm{AMC}$ values are generally very small $(<0.001)$ for these solutes, supporting the notion that at low watersurface coverage the adsorption of multiple solutes on hydrophilic solids would be largely linear and noncompetitive. As noted, the $S_{\mathrm{w}} K_{\mathrm{d}} / \mathrm{AMC}$ values for polar DNB and DNT are greater by $1-2$ orders of magnitude over those of the low-polarity solutes, although the values for DNB and DNT $(0.00668-0.0365)$ correspond nonetheless to a low surface coverage. The cause for the higher surface coverage for polar solutes will be considered later. 
The water film on silica or alumina referred to is considered to be only about one molecular-layer thick, formed supposedly via the $\mathrm{H}$-bonding of water with surface hydroxyls $(16,27)$, and thus does not extend much beyond the first layer. As such, an organic solute may adsorb more effectively than excess water by London forces on the water film because the solute has a greater molar polarizability than water (15). Thus, for relatively nonpolar solutes, London forces should be the main cause for adsorption. Here the solute adsorption heat should be low because of the rapid decrease of the London force with the distance of separation by the water film and the absence of solute condensation onto the water film. For polar solutes (e.g., DNT), the adsorption is presumably facilitated by additional polargroup interactions with the water film, considering their moderately high $K_{\mathrm{d}}$ and very high $S_{\mathrm{w}}$ values. This interaction enhances the polar-solute monolayer coverage and partially offsets the solute hydrophilicity. Thus, the $K_{d}$ values for a mixed group of polar and nonpolar solutes would not likely be dictated by the solute water solubility $\left(S_{\mathrm{w}}\right)$ or the octanolwater partition coefficient $\left(K_{\text {ow }}\right)$. The previously observed correlation of $K_{\mathrm{d}}$ with solute hydrophilicity $(8,10)$ could have resulted from the use of limited low-polarity solute $K_{\mathrm{d}}$ data. As shown in Table 1, the $\log K_{\text {ow }}$ values of the studied solutes differ by more than 1000 fold, whereas the measured $K_{\mathrm{d}}$ values in Table 2 differ only by 6 fold on silica and by 10 fold on alumina.

It is noted with interest that the adsorption of polar solutes on poorly hydrophilic mineral surfaces yields contrasting results on solute uptake and isotherm linearity. A good example of such surfaces is the siloxane plane in montmorillonite, which is more readily wet by a polar liquid (e.g., EGME) than by water because water has an exceptionally high cohesive-energy density (28). In essence, the availability of siloxane layers in a montmorillonite for adsorbing solutes depends strongly on the hydrating power of the exchangeable cation(s) intercalated between the siloxane layers (29). Typical strongly hydrating cations are $\mathrm{Ca}^{2+}, \mathrm{Mg}^{2+}$, and $\mathrm{Na}^{+}$, and weakly hydrating cations are $\mathrm{K}^{+}, \mathrm{Cs}^{+}$, and $\mathrm{NH}_{4}^{+}$(29). As observed, adsorption of polar nitroaromatic solutes (e.g., DNT) from water on clays saturated with poorly hydrating cations (e.g., $\mathrm{K}^{+}$) is substantial and nonlinear, reflecting that polar solutes adsorb (condense) more readily than water onto available poorly hydrating siloxane planes $(30,31)$. However, by replacing $\mathrm{K}^{+}$with $\mathrm{Ca}^{2+}$ in the clay, the availability of siloxane layers is seriously inhibited by the $\mathrm{Ca}^{2+}$-solvated water and the solute adsorption is thus sharply reduced (29, $31-33)$. This result is similar to that with hydrophilic silica and alumina, in which the preferred adsorption of water on minerals weakens the competitive solute adsorption. The observed low-concentration $K_{\mathrm{d}}$ values for all nitroaromatic solutes with clay siloxane surfaces show no significant correlation with the solute hydrophilicity $\left(S_{\mathrm{w}}\right.$ or $\left.K_{\mathrm{ow}}\right)$ (31).

As noted here, the $K_{\mathrm{d}}$ values of low-polarity solutes with silica are always greater than those with alumina, in which the differences for TCB and LIN are closely related to the solid surface areas, as recognized earlier $(8,13)$, whereas the results for PHN and PYR are only partially related to the surface areas. Reasons for these discrepancies are not immediately clear and will be subject to further investigations. Moreover, the $K_{\mathrm{d}}$ values of low-polarity solutes also show no strong dependence on the solid surface charge (10). In contrast, the $K_{\mathrm{d}}$ values for the polar solutes (DNT and DNB) with the two solids are relatively comparable and much higher in magnitude than expected from their high water solubilities. The latter finding suggests that the adsorption of polar solutes involves additional polar interactions and/or $\mathrm{H}$-bonding with the water-film surface.

The different ionic-strength effects on $K_{\mathrm{d}}$ observed for polar and nonpolar solutes support the presumed solute polarity effect. As shown in Table 2, when the solution ionic strength increased from 0.01 to $0.05 \mathrm{M} \mathrm{CaCl}_{2}$, no significant change in $K_{\mathrm{d}}$ occurred for LIN, PHN, and PYR, a result conciliatory with the assumed primary adsorptive force (i.e., London force) for nonpolar solutes. Contrarily, the same change in ionic strength resulted in a significant decrease in $K_{\mathrm{d}}$ for polar DNT, consistent with the notion that the net surface charges, which attract polar solutes, decrease with increasing ionic strength. Similarly, when the solution $\mathrm{pH}$ increased to 8.0 (i.e., $\geq 1$ unit above the PZC), the $K_{\mathrm{d}}$ for PHN/ alumina did not vary significantly, whereas the $K_{\mathrm{d}}$ for DNT/ alumina showed a substantial increase, the latter being indicative of an increased surface charge that promotes the solute dipole-surface charge interaction.

In summary, the postulated molecular interactions of polar and nonpolar solutes with hydrophilic silica and alumina account effectively for the observed outstanding adsorption characteristics, i.e., the isotherm linearity, low exothermic heats, and noncompetitive uptakes. The noncompetitive adsorption between solutes as illustrated in this study has an important implication on individual solute behaviors in multi-solute natural systems. The different adsorptive forces hypothesized for polar and nonpolar solutes are underscored by the different solute $K_{\mathrm{d}}$ responses to ionic strength and $\mathrm{pH}$. At this point, however, more fundamental inputs are still needed to shed light on all relevant molecular and surface parameters that influence the linear adsorption of both polar and nonpolar solutes on various hydrophilic minerals.

\section{Acknowledgments}

The research was supported by the Ministry of Science and Technology (2007CB407301), the Chinese Academy of Sciences (KZCX3-SW-431), and the Chinese Natural Science Foundation (20667003). The use of trade, brand, or product names in this article is for identification purposes only and does not imply endorsement by the U.S. Government.

\section{Literature Cited}

(1) Chiou, C. T.; Peters, L. J.; Freed, V. H. A physical concept of soil-water equilibria for nonionic organic compounds. Science 1979, 206, 831-832.

(2) Chiou, C. T.; Porter, P. E.; Schmedding, D. W. Partition equilibria of nonionic organic compounds between soil organic matter and water. Environ. Sci. Technol. 1983, 17, 227-231.

(3) Karickhoff, S. W.; Brown, D. S.; Scott, T. A. Sorption of hydrophobic pollutants on natural sediments. Water Res. 1979 , 13, $241-248$

(4) Schwarzenbach, R. P.; Westall, J. Transport of nonpolar organic compounds from surface water to groundwater. Environ. Sci. Technol. 1981, 15, 1360-1367.

(5) Chiou, C. T.; Kile, D. E.; Rutherford, D. W.; Sheng, G.; Boyd, S. A. Sorption of selected organic compounds from water to a peat soil and its humic-acid and humin fractions: Potential sources of the sorption nonlinearity. Environ. Sci. Technol. 2000, 34, 1254-1258.

(6) Evanko, C. R.; Dzombak, D. A. Influence of structural features on sorption of NOM-analogue organic acids to goethite. Environ. Sci. Technol. 1998, 32, 2846-2855.

(7) Keoleian, G. A.; Curl, R. L. Effects of humic acid on the adsorption of tetrachlorobiphenyl by kaolinite. In Aquatic Humic Substances: Influence on the Fate and Treatment of Pollutants; Suffet, I. H., MacCarthy, P., Eds.; Adv. Chem. Series 219; American Chemical Society: Washington, DC, 1989.

(8) Backhus, D. A. Colloids in groundwater: Laboratory and field studies of their influence on hydrophobic organic contaminants; Ph.D. Dissertation, Massachusetts Institute of Technology, Cambridge, MA, 1990.

(9) Huang, W.; Schlautman, M. A.; Weber, W. J., Jr. A distributed reactivity model for sorption by soils and sediments. 5 . The influence of near-surface characteristics in mineral domains. Environ. Sci. Technol. 1996, 30, 2993-3000.

(10) Mader, B. T., Goss, K. U.; Eisenreich, S. J. Sorption of nonionic, hydrophobic organic chemicals to mineral surfaces. Environ. Sci. Technol. 1997, 31, 1079-1086. 
(11) Boucher, F. R.; Lee, G. F. Adsorption of lindane and dieldrin pesticides on unconsolidated aquifer sands. Environ. Sci. Technol. 1972, 6, 538-543.

(12) Hundal, L. S.; Thompson, M. L.; Laird, D. A.; Carmo, A. M. Sorption of phenanthrene by reference smectites. Environ. Sci. Technol. 2001, 35, 3456-3461.

(13) Huang, W.; Weber, W. J., Jr. Thermodynamic considerations in the sorption of organic contaminants by soils and sediments. 1. The isosteric heat approach and its application to model inorganic sorbents. Environ. Sci. Technol. 1997, 31, 3238-3243.

(14) Noll, L. A. Adsorption of aqueous benzene onto hydrophobic and hydrophilic surfaces. Colloids Surf. 1987, 28, 327-329.

(15) Manes, M. Activated carbon adsorption fundamentals. In Encyclopedia of Environmental Analysis and Remediation; Myers, R. A., Ed.; Wiley: NY, 1998; pp 26-68.

(16) Stumm, W.; Morgan, J. J. Aquatic Chemistry, 3rd ed.; WileyInterscience: New York, 1996; pp 533-568.

(17) Chiou, C. T.; Kile, D. E. Deviation from sorption linearity on soils of polar and nonpolar organic compounds at low relative concentrations. Environ. Sci. Technol. 1998, 32, 338-343.

(18) Newcombe, G.; Donati, C.; Drikas, M.; Hayes, R. Adsorption onto activated carbon: electrostatic and non-electrostatic interactions. Water Supply 1996, 14, 129-144.

(19) Mackay, D.; Shiu, W. Y.; Ma, K.-C. Illustrated Handbook of Physical-Chemical Properties and Environmental fate for Organic Chemicals - Monoaromatic Hydrocarbons, Chlorobenzenes, and PCBs, Vol. I; Lewis Publishers: Boca Raton, FL, 1992.

(20) Mackay, D.; Shiu, W. Y.; Ma, K.-C. Illustrated Handbook of Physical-Chemical Properties and Environment al Fate for Organic Chemicals - Polynuclear Aromatic Hydrocarbons, Polychlorinated Dioxins, and Dibenzofurans, Vol. II; Lewis Publishers: Boca Raton, FL, 1992.

(21) Mackay, D.; Shiu, W. Y.; Ma, K.-C. Illustrated Handbook of Physical-Chemical Properties and Environmental Fate for Organic Chemicals - Oxygen, Nitrogen, and Sulfur Containing Compounds, Vol. IV; Lewis Publishers: Boca Raton, FL, 1995.

(22) Mackay, D.; Shiu, W. Y.; Ma, K.-C. Illustrated Handbook of Physical-Chemical Properties and Environmental Fate for Organic Chemicals - Pesticide Chemicals, Vol. V; Lewis Publishers: Boca Raton, FL, 1997.
(23) Syracuse Research Corporation. The Physical Properties Database. http://www.syrres.com/esc/physprop.htm.

(24) May, W. E.; Wasik, S. P.; Miller, M. M.; Tewari, Y. B.; BrownThomas, J. M.; Goldberg, R. N. Solution thermodynamics of some slightly soluble hydrocarbons in water. J. Chem. Eng. Data 1983, 28, 197-200.

(25) Li, H.; Teppen, B. J.; Johnston, C. T.; Boyd, S. A. Thermodynamics of nitroaromatic compound adsorption from water by smectite clay. Environ. Sci. Technol. 2004, 38, 5433-5442.

(26) Chiou, C. T. Partition and Adsorption of Organic Contaminants in Environmental Systems; Chapter 4; Wiley-Interscience: Hoboken, NJ, 2002.

(27) Fripiat, J. J. Surface chemistry and soil science. In Experimental Pedology; Hallsworth, E. G., Crawford, D. V., Eds.; Butterworths: London, 1965.

(28) Chiou, C. T.; Rutherford, D. W. Effects of exchanged cation and layer charge on the sorption of water and EGME vapors on montmorillonite clays. Clays Clay Miner. 1997, 45, 867-880.

(29) Weissmahr, K. W.; Haderlein, S. B.; Schwarzenbach, R. P. In situ spectroscopic investigations of adsorption mechanisms of nitroaromatic compounds at clay minerals. Environ. Sci. Technol. 1997, 31, 240-247.

(30) Haderlein, S. B.; Weissmahr, K. W.; Schwarzenbach, R. P. Specific adsorption of nitroaromatic explosives and pesticides to clay minerals. Environ. Sci. Technol. 1996, 30, 612-622.

(31) Haderlein, S. B.; Schwarzenbach, R. P. Adsorption of substituted nitrobenzenes and nitrophenols to mineral surfaces. Environ. Sci. Technol. 1993, 27, 316-326.

(32) Chappell, M. A.; Laird, D. A.; Thompson, M. L.; Li, H.; Teppen, B. J.; Aggarwal, V.; Johnston, C. T.; Boyd, S. A. Influence of smectite hydration and swelling on atrazine sorption behavior. Environ. Sci. Technol. 2005, 39, 3150-3157.

(33) Aggarwal, V.; Li, H.; Teppen, B. J. Triazine adsorption by saponite and beidellite clay minerals. Environ. Toxicol. Chem. 2006, 25, 392-399.

Received for review April 24, 2006. Revised manuscript received September 6, 2006. Accepted September 11, 2006.

ES0609809 